\title{
Familial risk for gastric carcinoma: an updated study from Sweden
}

\author{
K Hemminki ${ }^{1,2}$, J Sundquist' and J Ji*,I \\ 'Center for Family and Community Medicine, Karolinska Institute, 14183 Huddinge, Sweden; ${ }^{2}$ Division of Molecular Genetic Epidemiology, German \\ Cancer Research Center (DKFZ), Im Neuenheimer Feld 580, 69I 20 Heidelberg, Germany
}

Reliable data on familial risks are important for clinical counselling and cancer genetics. However, the estimates of familial risk of gastric cancer vary widely. We examined the risk of familial gastric cancer using the updated Swedish Family-Cancer Database with 5358 patients among offspring and 36486 patients among parents. There were 133 families with one parent and one offspring diagnosed with gastric cancer, and 20 families with two affected offspring. Familial standardised incidence ratios (SIRs) were 1.63 and 2.93 when parents and siblings presented with gastric cancer, respectively. The high sibling risk was owing to cancer in the corpus (SIR 7.28). The SIR for cardia cancer was 1.54 when parents were diagnosed with any gastric cancer. Cardia cancer associated with oesophageal cancer, particularly with oesophageal adenocarcinoma. Among specific histologies, signet ring cancer showed an increase. A few associations were noted for discordant sites, including the urinary bladder and the endometrium. $H$. pylori infection, although not measured in the present study, is probably an important risk factor for the high sibling risk of corpus cancer. Familial clustering of cardia cancer is independent of $H$. pylori infection, and may have a genetic basis. The familial association of cardia cancer with oesophageal adenocarcinoma may provide aetiological clues.

British Journal of Cancer (2007) 96, 1272- 1277. doi:I0.1038/sj.bjc.6603722 www.bjcancer.com

Published online 3 April 2007

(c) 2007 Cancer Research UK

Keywords: gastric cancer; cardia cancer; corpus cancer; familial risk

\begin{abstract}
Although the incidence of gastric cancer has declined in the past several decades, it remains the second most common cause of cancer-related deaths in the world (Parkin et al, 2001). It has been estimated that there were more than 870000 deaths from this disease in the year 2000 (Pisani et al, 1993). In Sweden, gastric cancer amounts to $2.3 \%$ of all malignancies (Center for Epidemiology, 2002). Approximately $90 \%$ of gastric cancers are adenocarcinomas, whereas leiomyosarcomas, carcinoids and undifferentiated tumours are rare, making up most of the remaining 10\%. According to the Lauren classification, adenocarcinomas can be subdivided into two histological types, the intestinal type, with a greatly declined incidence rate, and the diffuse type, exhibiting a relatively constant rate. Most gastric carcinomas are located distal to the cardia (corpus cancer), which has markedly declined in the Western countries, including Sweden; about $25 \%$ are localised proximally in the cardia (cardia cancer), with a relatively stable incidence (Desoubeaux et al, 1999; Ekstrom et al, 1999; Ekstrom et al, 2000).

Helicobacter pylori is a main risk factor of distal gastric cancer (Huang et al, 1998; Crew and Neugut, 2004). The infection causes a chronic active inflammation in the gastric mucosa and, in a subgroup, gastritis arises in the corpus, which is a risk factor for gastric cancer (Uemura et al, 2001). Other risk factors of distal gastric cancer include dietary nitrite, salt, and smoking (Hirohata and Kono, 1997; Ye et al, 1999; Kobayashi et al, 2002; Ngoan and Yoshimura, 2003; Crew and Neugut, 2004). As for cardia cancer, H. pylori infection appears not to be important and there may even be an inverse association (Crew and Neugut, 2004; Ye et al, 2004). Smoking, dietary nitrite and obesity may be risk factors of cardia cancer (Lagergren et al, 1999b; Ye et al, 1999; Crew and Neugut,
\end{abstract}

*Correspondence: Dr J ji; E-mail: jianguang.ji@ki.se

Received 24 January 2007; revised 5 March 2007; accepted 8 March 2007; published online 3 April 2007
2004). A positive family history is a risk of gastric cancer but the reported risks ranged widely from about 1.3 to 3.0 (La Vecchia et al, 1992; Munoz et al, 1997; Lissowska et al, 1999; Lagergren et al, 2000; Hemminki and Jiang, 2002b; Amundadottir et al, 2004; Kerber and O'Brien, 2005). Gastric cancer is a manifestation of several cancer syndromes, such as hereditary nonpolyposis colorectal carcinoma (HNPCC, particularly in Japanese families), adenomatous polyposis (FAP) and some other rare syndromes (Lynch and de la Chapelle, 2003).

In view of the varying familial risk estimates for gastric cancer, we examined here the risk using the newest update of the nation-wide Swedish Family-Cancer Database, which covered offspring between birth and age 72 years and their parents. Compared with the earlier study from this Database based on 58 familial cases in the first-degree relatives (Hemminki and Jiang, 2002b), the extended population included 153 familial gastric cancers, allowing a more exact definition of the familial risk and analysis by specific histological types and anatomical sites. A familial risk of cardia cancer, if demonstrated, would be independent of infection by $H$. pylori (Ye et al, 2004). Besides, the associations of gastric cancer with other tumours in families were also examined. The special properties of the Database include registered sources of family relationships and medically verified cancer cases with practically complete national coverage. This is the largest study published on familial gastric cancer.

\section{MATERIALS AND METHODS}

Statistics Sweden maintains a 'Multigeneration Register' where children, offspring, born in Sweden in 1932 and later are registered with their biological parents and they are organised as families (Hemminki et al, 2001a). The latest version of the Multigeneration Register, which has been incorporated in the Database, includes supplementary data from church records on index persons 
domiciled in Sweden between 1947 and 1961, including information about biological parents, children, siblings, and adoptions. This Register was linked by the individually unique national registration number to the Cancer Registry to create the Swedish Family-Cancer Database (MigMed2), which was updated in 2006 with cancer cases from 1958 to 2004. The data on families and cancers have a complete coverage, barring some groups of deceased offspring, which affected those born in the 1930s and those who died before 1991. Although this small group of offspring with missing links to parents has a negligible effect on the estimate of familial risk (Dong and Hemminki, 2001), we limited the present study to offspring whose parents were known to eliminate the possibility of bias. Cancer registration is currently considered to be close to $100 \%$ (Center for Epidemiology, 2002). A four-digit diagnosis code according to the 7th revision of the International Classification of Diseases (ICD-7) has been used. The following ICD-7 codes were grouped: 'upper aero digestive tract' cancer codes 161 (larynx) and 140-148 (lip, mouth, and pharynx), except for code 142 (salivary glands), 'non-Hodgkin lymphoma' codes 200 and 202, and 'leukaemia' codes 204-207 (leukaemia), 208 (polycytemia vera) and 209 (myelofibrosis). Rectal cancer, ICD-7 code 154, was subdivided into the anus (squamous cell carcinoma, 154.1) and mucosal rectum (154.0). Basal cell carcinoma of the skin is not registered in the Cancer Registry. Lymphomas are classified as independent entities irrespective of their anatomic sites. Only the first gastric cancer was considered in the present study, and a total of 5358 offspring and 36486 parents were diagnosed with gastric cancer in the Database. Most Swedish counties recorded gastric cancer with histopathological data by the Systematised Nomenclature of Medicine (SNOMED, http:// snomed.org) from year 1990, but the nation-wide application of SNOMED code was available after 1993. To avoid loss of cases, we included those cases diagnosed between years 1990 and 2004 for the analysis of familial risks by histology.

Family history of gastric cancer was determined for each offspring in the beginning of the follow-up period. Gastric cancer incidence was compared among offspring with or without family history. If not specified otherwise, the follow-up was started for each offspring at birth, immigration or on 1 January 1961, whichever was the latest time. Follow-up was terminated at the diagnosis of first cancer, death, emigration or the closing date of the study on 31 , December 2004. Standardised incidence ratios (SIRs) were used to measure the cancer risks for offspring according to the occurrence of cancers in their families. SIRs were calculated and results are shown for offspring gastric cancer when the parent, sibling or parent and sibling had any cancer, that is using parents, siblings or parents and siblings as probands in mutually exclusive categories. When more than two affected offspring were found in any family, they were counted as independent events.

Parents' ages were not limited, but offspring were $0-72$ years of age. SIRs were calculated as the ratio of observed $(\mathrm{O})$ to expected (E) number of cases. The expected numbers were calculated from 5 -year-age, gender, tumour type, period, socioeconomic status (six groups), and residential area (three groups) specific standard incidence rates for all offspring lacking a family history (Esteve et al, 1994). Confidence intervals (95 and 99\% CI) were calculated assuming a Poisson distribution, and they were rounded to the nearest two decimals (Esteve et al, 1994). Risks for siblings were calculated using the cohort method, as described elsewhere (Hemminki et al, 2001b).

\section{RESULTS}

\section{Familial gastric cancer}

The Swedish Family-Cancer Database, which covered years 1961 2004 from the Swedish Cancer Registry, included 5358 offspring
(0-72 years) and 36486 parents with gastric cancer. Familial risks for offspring gastric cancer were calculated by using parents, siblings or parents, and siblings as probands, and by adjusting for age, period, residential area, and socio-economic status (Table 1). Only those cancer sites with at least five offspring gastric cancers (column 'parent only') were listed in Table 1. Offspring gastric cancers were significantly increased when a parent (SIR 1.63) or a sibling (2.93) was diagnosed with gastric cancer; the risks were significant even at a $1 \%$ level, as indicated by underlined SIRs. The associations were mainly related to gastric adenocarcinoma. In order to compare risks for offspring of affected parents and for siblings, we limited the parental ages to 72 years, and the SIR was still lower, $1.64(N=75,95 \%$ CI $1.29-2.06)$. The risks were increased to $1.76(N=34,95 \%$ CI $1.22-2.46)$ for offspring of affected parents and to $3.99(N=6,95 \%$ CI $1.43-8.73)$ for siblings if the subjects were diagnosed at ages younger than 50 years. Conversely, the SIRs were decreased to $1.58(N=99,95 \%$ CI 1.29 $1.93)$ and $2.63(N=14,95 \%$ CI $1.43-4.43)$ if diagnostic ages were 50 years and higher. We further analysed the risk for those diagnosed after year 1991; the SIRs were $1.79(N=126,95 \%$ CI $1.49-2.13)$ and $2.89(N=17,95 \%$ CI $1.68-4.63)$ in offspring of affected parents and siblings, respectively.

Offspring gastric cancer was associated with paternal genital cancers (2.76). Among siblings, gastric cancer was associated with endometrial (1.65) and urinary bladder cancers (1.67). The risk was of borderline significance for colorectal cancers $(1.37,95 \%$ CI $0.99-1.87$ ) among siblings. When a parent and a sibling were affected with lung cancer, the SIR for offspring gastric cancer was significantly increased to 4.19 . In the 21 families with gastric and endometrial cancers among siblings, three siblings were diagnosed with an endometrial tumour before age 45 years; for parents in these families, three pancreatic, two gastric, two prostate cancers, and one colon cancer (age $=40$ ) were observed. For the 24 families with gastric and urinary bladder cancers among siblings, three parents were noted with gastric cancer, two parents with pancreatic cancer, and one parent each with liver, lung, breast, and prostate cancers, respectively.

\section{Familial cardia and corpus cancers}

Because of the different risk factors for cardia and corpus cancers, we further analyzed the familial risks for the two anatomical sites based on SNOMED. For cardia cancer (Table 2), significantly increased SIRs were observed when parents were diagnosed with all oesophageal cancer (2.94), oesophageal adenocarcinoma (5.67), and gastric cancer (1.54). When cardia cancer was identified by the ICD-7 code and diagnosed after age 49 years (covering years 1970-2004, data not shown), a significant association was noted for nervous system tumours ( $\mathrm{SIR}=2.42, N=9,95 \% \mathrm{CI} 1.10-4.62$ ) among siblings. Nervous system tumours were further analysed by histology; the SIR was $4.48(N=5,95 \%$ CI $1.41-10.55)$ and 3.36 $(N=5,95 \%$ CI $1.06-7.91)$ when siblings presented with glioblastoma and any glioma, respectively.

The risk for offspring corpus cancer was significantly increased to 2.50 and 3.70 when parents were diagnosed with gastric and corpus cancers, respectively (Table 2). The risk was high when siblings were presented with gastric cancer (7.28). For discordant cancer sites, offspring corpus cancer was associated with maternal breast cancer (1.84) and non-Hodgkin's lymphoma among sibling (4.77). An association was also noted for maternal ovarian cancer $(2.02, N=17,95 \%$ CI $1.17-3.24)$ when corpus cancer was recorded by ICD-7 (data not shown).

\section{Familial gastric cancer by histology}

We further analyzed the risks for histology specific gastric cancer in offspring by familial gastric cancer (Table 3). Offspring unspecified adenocarcinomas showed significantly increased risks 
Table I Risks for gastric cancer in offspring by familial cancers (|96|-2004)

\begin{tabular}{|c|c|c|c|c|c|c|c|c|c|c|c|c|}
\hline $\begin{array}{l}\text { Familial cancer sites } \\
\text { Upper aerodigestive tract }\end{array}$ & \multicolumn{4}{|c|}{ Parently only } & \multicolumn{4}{|c|}{ Sibling only } & \multicolumn{4}{|c|}{ Parent and sibling } \\
\hline Oesophagus & 14 & 1.14 & 0.62 & 1.92 & 5 & 1.95 & 0.61 & 4.58 & 0 & & & \\
\hline Stomach & 133 & 1.63 & 1.36 & 1.93 & 20 & 2.93 & 1.79 & 4.53 & 2 & 4.93 & 0.46 & 18.13 \\
\hline Adenocarcinoma & 116 & 1.63 & 1.34 & 1.95 & 18 & 2.90 & 1.71 & 4.59 & 2 & 6.02 & 0.57 & 22.13 \\
\hline Colorectum & 182 & 1.04 & 0.90 & 1.21 & 41 & 1.37 & 0.99 & 1.87 & 4 & 1.17 & 0.30 & 3.03 \\
\hline Lung & 112 & 1.10 & 0.90 & 1.32 & 32 & 1.34 & 0.92 & 1.90 & 6 & 4.19 & 1.51 & 9.19 \\
\hline Breast & 150 & 1.04 & 0.88 & 1.22 & 84 & 1.10 & 0.88 & 1.36 & 3 & 0.49 & 0.09 & 1.45 \\
\hline Cervix & 31 & 1.06 & 0.72 & 1.50 & 12 & 1.17 & 0.60 & 2.04 & 0 & & & \\
\hline Endometrium & 41 & 1.08 & 0.77 & 1.47 & 21 & 1.65 & 1.02 & 2.53 & । & 2.92 & 0.00 & 16.75 \\
\hline Ovary & 42 & 1.25 & 0.90 & 1.69 & 20 & 1.58 & 0.97 & 2.45 & 0 & & & \\
\hline Other female genital & 8 & 1.12 & 0.48 & 2.21 & 0 & & & & 0 & & & \\
\hline Prostate & 207 & 1.00 & 0.87 & 1.15 & 40 & 1.11 & 0.79 & 1.51 & 5 & 0.83 & 0.26 & 1.96 \\
\hline Nervous system & 33 & 0.92 & 0.63 & 1.29 & 25 & 1.32 & 0.85 & 1.95 & 0 & & & \\
\hline Thyroid gland & 10 & 0.96 & 0.46 & 1.78 & 9 & 1.55 & 0.70 & 2.96 & 0 & & & \\
\hline Endocrine glands & 12 & 0.55 & 0.28 & 0.97 & 16 & 1.55 & 0.88 & 2.52 & 0 & & & \\
\hline Connective tissue & 13 & 1.45 & 0.77 & 2.49 & 6 & 1.87 & 0.67 & 4.10 & 0 & & & \\
\hline Non-Hodgkin's lymphoma & 49 & 1.25 & 0.92 & 1.65 & 19 & 1.34 & 0.80 & 2.09 & 0 & & & \\
\hline Hodgkin's disease & 8 & 1.23 & 0.53 & 2.44 & 2 & 0.63 & 0.06 & 2.30 & 0 & & & \\
\hline Myeloma & 24 & 1.02 & 0.65 & 1.51 & 2 & 0.50 & 0.05 & 1.83 & 0 & & & \\
\hline Leukemia & 35 & 0.85 & 0.59 & 1.18 & 10 & 1.03 & 0.49 & 1.90 & 0 & & & \\
\hline All & 1104 & 1.04 & 0.98 & 1.10 & 231 & 1.18 & 1.04 & 1.35 & 205 & 1.26 & 1.09 & 1.44 \\
\hline
\end{tabular}

$\mathrm{Cl}=$ confidence interval, $\mathrm{O}$, observed cases. Bold type: $95 \% \mathrm{Cl}$ does not include 1.00 ; underline type, $99 \% \mathrm{Cl}$ does not include 1.00 .

Table 2 Risks for cardia and corpus cancers in offspring by familial cancers (1993-2004)

\begin{tabular}{|c|c|c|c|c|c|c|c|c|}
\hline \multirow{2}{*}{$\begin{array}{l}\text { Cancer sites } \\
\text { Risk for cardia cancer }\end{array}$} & \multirow{2}{*}{$\mathbf{0}$} & \multirow[t]{2}{*}{ SIR } & \multicolumn{2}{|c|}{$95 \% \mathrm{Cl}$} & \multirow[t]{2}{*}{0} & \multirow[t]{2}{*}{ SIR } & \multicolumn{2}{|c|}{$95 \% \mathrm{Cl}$} \\
\hline & & & & & & & & \\
\hline Oesophagus & 8 & 2.94 & 1.26 & 5.82 & I & 1.83 & 0.00 & 10.52 \\
\hline Adenocarcinoma & 3 & 5.67 & 1.07 & 16.80 & 0 & & & \\
\hline SCC & 4 & 2.17 & 0.57 & 5.62 & 0 & & & \\
\hline Stomach & 28 & 1.54 & 1.02 & 2.23 & । & 0.67 & 0.00 & 3.83 \\
\hline \multicolumn{9}{|l|}{ Risk for corpus cancer } \\
\hline Oesophagus & 0 & & & & I & 6.27 & 0.00 & 35.94 \\
\hline Stomach & 12 & 2.50 & 1.29 & 4.38 & 3 & 7.28 & 1.37 & 21.55 \\
\hline Cardia & 0 & & & & 0 & & & \\
\hline Corpus & 9 & 3.70 & 1.68 & 7.06 & I & 2.33 & 0.00 & 13.33 \\
\hline Breast & 15 & 1.84 & 1.02 & 3.04 & 4 & 0.89 & 0.23 & 2.31 \\
\hline
\end{tabular}

$\mathrm{Cl}=$ confidence interval, O, observed cases. Bold type: $95 \% \mathrm{Cl}$ does not include 1.00 ; underline type, $99 \% \mathrm{Cl}$ does not include 1.00 .

when parents (1.79) or siblings (2.90) were diagnosed with gastric cancer. The risks for signet ring cancer were increased when parents (1.99) or siblings (5.40) presented with gastric cancer. Five of these signet ring cancers were located in the corpus and two in cardia; for the others the location was unspecified.

\section{DISCUSSION}

The sharp decline in gastric cancer incidence during the past decades suggests that environmental risk factors play an important role in its aetiology. A Nordic twin study estimated that $62 \%$ variation in gastric cancer were owing to random environmental effects, $10 \%$ from shared environmental factors, and $28 \%$ from heritable effects (Lichtenstein et al, 2000); however, only the first figure was significant. Genetic and environmental components for gastric cancer have also been estimated based on the Swedish Family-Cancer Database (Czene et al, 2002). The results agreed with the twin study on the importance of random environmental effects (71\%). Both adult (15\%) and childhood (13\%) shared environmental effects were also significant. Only $1 \%$ was assigned for heritable effects. Another piece of evidence on the 
Table 3 Risks for offspring histology specific gastric cancer by familial gastric cancers, (1990-2004)

\begin{tabular}{|c|c|c|c|c|c|c|c|c|}
\hline $\begin{array}{l}\text { Histologies } \\
\text { Stomach, all }\end{array}$ & $\frac{0}{128}$ & $\begin{array}{l}\text { SIR } \\
1.76\end{array}$ & \multicolumn{2}{|c|}{$95 \% \mathrm{Cl}$} & $\begin{array}{l}\mathbf{0} \\
17\end{array}$ & $\begin{array}{l}\text { SIR } \\
2.80\end{array}$ & \multicolumn{2}{|c|}{$95 \% \mathrm{Cl}$} \\
\hline Adenocarcinoma & 81 & 1.79 & 1.42 & 2.23 & 11 & 2.90 & 1.44 & 5.20 \\
\hline Gastrointestinal stromal tumours & 3 & 1.23 & 0.23 & 3.63 & I & 5.34 & 0.00 & 30.60 \\
\hline
\end{tabular}

$\mathrm{Cl}=$ confidence interval, $\mathrm{O}$, observed cases. Bold type: $95 \% \mathrm{Cl}$ does not include 1.00; underline type, $99 \% \mathrm{Cl}$ does not include 1.00 .

environmental aetiology of gastric cancer has been the concordance of gastric cancer between spouses (Hemminki and Jiang, 2002a; Amundadottir et al, 2004).

In the present study 35 cancer sites, three groups of probands, different age groups, and histological types were covered and some associations were likely to appear by chance. However, only one SIR was significantly decreased, compared with 10 significantly increased ones (Table 1), suggesting that chance findings could be limited. We also calculated the $99 \%$ CI to deal with this issue; true findings could be more possible if they were significant at $1 \%$ level. Additionally, significant associations were examined for biological plausibility and consistency with other literatures, as discussed later. Another minor limitation of this study may be the lack of parental links of a few offspring born in the 1930s, who died before 1991. Such families were excluded from the present study as only offspring with known parents were considered. Whether this caused a bias, we calculated the familial risk for offspring diagnosed after year 1991. The SIRs were essentially unchanged, suggesting that the present risk estimates were unbiased. Additionally, data on possible confounding factors, such as diet, $H$. pylori infection, and smoking, were unavailable in the Database: However, the adjustment for socioeconomic status could partly decrease their effects. Moreover, the low association between gastric and lung cancer (1.10, Table 1, parental probands) suggested that smoking was not a confounder of the familial associations.

In the present study we provided evidence for familial risk of gastric cancer in first-degree relatives, which may be caused by heritable and/or shared environmental effects. Significant associations were observed for offspring of affected parents with a SIR of 1.63 and for siblings with a SIR of 2.93. However, sibling risks were not fully comparable with offspring risks in this study, because of the different age distribution for the offspring and parental generations in our Database. To compare the risks for offspring and siblings, the maximal parental age was limited to 72 years; however the SIR for offspring (1.64) was unaltered. The difference between sibling (3.99) and offspring risks (1.76) was even higher when the age of onset was limited to lower than 50 years. The high sibling risks may be owing to shared childhood environmental factors or to a recessive mode of inheritance, or both. A recent study by Chang et al (2002) showed that the prevalence of $H$. pylori infection was $89 \%$ when a sibling had a history of gastric cancer, giving an OR was 5.3; this was higher than the OR of 2.1 when a parent presented with gastric cancer. Thus subjects who had a sibling with gastric cancer had a higher risk of $H$. pylori infection than subjects with a parental history of gastric cancer.

H. pylori infections are still common in Sweden. A sample of 1000 Swedes were randomly selected for oesophago-gastroduodenoscopy with biopsies and $H$. pylori serology and one-third of the subjects had a current infection and a further $10 \%$ had signs of past infection (Storskrubb et al, 2005). The prevalence of premalignant atrophy and intestinal metaplasia of the corpus was high among those with current and past infection while seronegativity excluded such precancerous conditions in the corpus. Many lines of evidence suggest that $H$. pylori infection is related to corpus cancer, rather than to cardia cancer (Siman et al, 1997; Eslick et al, 1999; Kelley and Duggan, 2003; Ye et al, 2004). Familial risk of corpus cancer was significantly increased when parents presented with any gastric cancer (2.50). The SIR was even high for concordant corpus cancers (3.70), suggesting that parents with corpus cancer were more likely carriers of $H$. pylori infection. The risk for corpus cancer among sibling was very high (7.28), in agreement with the evidence that cross-transmission of $H$. pylori infection was more common between siblings than between parents and offspring (La Vecchia et al, 1995; Goodman and Correa, 2000). The consistency with the transmission patterns of $H$. pylori infection, the high sibling risks, particularly for concordant corpus cancers, suggest that $H$. pylori infection was an important risk factor for the familial risk of corpus cancer in the present study.

Evidence was provided for an independent familial risk for cardia cancer in the offspring of affected parents diagnosed with gastric cancer (1.54). An earlier Swedish case-control study showed a moderate increase of cardia cancer among subjects with a familial history of gastric cancer in first-degree relatives. However, according to the authors, the result could be overestimated by reporting bias (Lagergren et al, 2000). A nonsignificant excess of cardia cancer was also noted in an US study among individuals reporting a family history of digestive tract cancers (Dhillon et al, 2001). In the present study, we observed a strong familial association between oesophageal adenocarcinoma and cardia cancer, giving an SIR of 5.67. Infection with $H$. pylori could not explain the observed associations, because neither cardia cancer nor oesophageal adenocarcinoma are related to $H$. pylori (Ye et al, 2004). Barrett's oesophagus is an established risk factor of both oesophageal adenocarcinoma (OR 43.5) and gastric cardia cancer (OR 4.4) (Lagergren et al, 1999a). Familial clustering of Barrett's oesophagus has been described (Crabb et al, 1985; Jochem et al, 1992), suggesting that the hereditary components for Barrett's oesophagus could be related to both cardia and oesophageal adenocarcinomas. Other factors, either genetic or environmental, may be also related to the family aggregations of cardia cancer (Chow et al, 1998; Zhang et al, 2006).

The histological classification used by the Swedish Cancer Registry does not specify intestinal and diffuse types of the Lauren classification and we were thus unable to contribute to the existing literature (Lehtola, 1978; Palli et al, 1994; Lissowska et al, 1999). Germ line mutations in the E-cadherin gene have been reported in Maori kindred with hereditary diffuse type gastric cancer (Guilford et al, 1998). In the present study, signet ring cancer resembles diffuse type carcinoma (Hamilton and Aaltonen, 2000), which showed a significant increase when parents or siblings presented with gastric cancer.

Gastric cancer is a component in several cancer syndromes, of which HNPCC, a dominant disease, is the most common (Lynch and de la Chapelle, 2003; Zhang et al, 2006). The most common cancer site in HNPCC is the colorectum, which showed a borderline increase among siblings in the present study. Other HNPCC-related cancers, endometrial and urinary bladder cancers, 
and brain gliomas were in excess but only among siblings, leaving the association to HNPCC in doubt.

The associations of gastric cancer with lung and bladder cancers could be related to tobacco smoking, because of the known familial aggregation of the smoking habit (Fisher, 1958; Tokuhata and Lilienfeld, 1963; Jonsson et al, 2004; Madden et al, 2004; Lorenzo Bermejo and Hemminki, 2005). Gastric and lung cancers could also be linked by $H$. pylori infection (Gocyk et al, 2000). However, corpus cancer showed no association with lung cancer. Male genital cancers associated with all gastric cancer, but the significance of this observation remains to be established. Human papilloma virus is a risk factor for male and female genital cancers (zur Hausen, 1999), and an association of gastric cancer with female genital cancers has been reported earlier (Goldgar et al, 1994). Corpus cancer associated with non-Hodgkin's lymphoma. $H$. pylori infection is an established cause of gastric lymphomas of mucosa-associated lymphoid tissue (Wotherspoon et al, 1991; Parsonnet et al, 1994), but we had no details of the non-Hodgkin's lymphoma subtypes. The association of corpus cancer with breast cancer was in line with a US case-control study (Dhillon et al, 2001). Second corpus cancer has been observed to be in excess after primary sporadic and familial breast cancers ( $\mathrm{Ji}$ and

\section{REFERENCES}

Amundadottir LT, Thorvaldsson S, Gudbjartsson DF, Sulem P, Kristjansson K, Arnason S, Gulcher JR, Bjornsson J, Kong A, Thorsteinsdottir U, Stefansson K (2004) Cancer as a complex phenotype: pattern of cancer distribution within and beyond the nuclear family. PLoS Med 1: e65

Center for Epidemiology (2002) Cancer Incidence in Sweden 2000. Stockholm: The National Board of Health and Welfware

Chang YW, Han YS, Lee DK, Kim HJ, Lim HS, Moon JS, Dong SH, Kim BH, Lee JI, Chang R (2002) Role of Helicobacter pylori infection among offspring or siblings of gastric cancer patients. Int J Cancer 101: 469-474

Chow WH, Blot WJ, Vaughan TL, Risch HA, Gammon MD, Stanford JL, Dubrow R, Schoenberg JB, Mayne ST, Farrow DC, Ahsan H, West AB, Rotterdam H, Niwa S, Fraumeni Jr JF (1998) Body mass index and risk of adenocarcinomas of the esophagus and gastric cardia. J Natl Cancer Inst 90: $150-155$

Crabb DW, Berk MA, Hall TR, Conneally PM, Biegel AA, Lehman GA (1985) Familial gastroesophageal reflux and development of Barrett's esophagus. Ann Intern Med 103: 52-54

Crew KD, Neugut AI (2004) Epidemiology of upper gastrointestinal malignancies. Semin Oncol 31: $450-464$

Czene K, Lichtenstein P, Hemminki K (2002) Environmental and heritable causes of cancer among 9.6 million individuals in the Swedish FamilyCancer Database. Int J Cancer 99: 260-266

Desoubeaux N, Le Prieur A, Launoy G, Maurel J, Lefevre H, Guillois JM, Gignoux M (1999) Recent time trends in cancer of the oesophagus and gastric cardia in the region of Calvados in France, 1978-1995: a population based study. Eur J Cancer Prev 8: 479-486

Dhillon PK, Farrow DC, Vaughan TL, Chow WH, Risch HA, Gammon MD, Mayne ST, Stanford JL, Schoenberg JB, Ahsan H, Dubrow R, West AB Rotterdam H, Blot WJ, Fraumeni Jr JF (2001) Family history of cancer and risk of esophageal and gastric cancers in the United States. Int J Cancer 93: $148-152$

Dong C, Hemminki K (2001) Modification of cancer risks in offspring by sibling and parental cancers from 2112616 nuclear families. Int J Cancer 92: $144-150$

Ekstrom AM, Hansson LE, Signorello LB, Lindgren A, Bergstrom R, Nyren O (2000) Decreasing incidence of both major histologic subtypes of gastric adenocarcinoma-a population-based study in Sweden. $\mathrm{Br}$ J Cancer 83: $391-396$

Ekstrom AM, Signorello LB, Hansson LE, Bergstrom R, Lindgren A, Nyren O (1999) Evaluating gastric cancer misclassification: a potential explana tion for the rise in cardia cancer incidence. J Natl Cancer Inst 91: $786-790$

Eslick GD, Lim LL, Byles JE, Xia HH, Talley NJ (1999) Association of Helicobacter pylori infection with gastric carcinoma: a meta-analysis. Am J Gastroenterol 94: 2373-2379
Hemminki, 2006); BRCA1, BRCA2, and E-cadherin gene may be shared genetic risk factors for the two cancer sites.

In conclusion, the present study showed that familial risks for concordant gastric cancers were higher for siblings than for parents and offspring. The excess sibling risk was mainly owing to corpus cancer for which $H$. pylori infection may be an important contributing factor; however, we have no data on $H$. pylori infection. Familial clustering for cardia cancer could be independent of $H$. pylori infection, as well as the association of cardia cancer with oesophageal adenocarcinoma. The associations with some discordant sites were probably explained by HNPCC and familial aggregation of smoking but all the discordant associations need to be confirmed.

\section{ACKNOWLEDGEMENTS}

The Family-Cancer Database was created by linking registries maintained by Statistics Sweden and the Swedish Cancer Register. The study was supported by the Deutsche Krebshilfe, the Swedish Cancer Society, the Swedish Council for Working Life and Social Research and the EU, LSHC-LT-2004-503465.
Esteve J, Benhamou E, Raymond L (1994) Statistical Methods in Cancer Research. Lyon: IARC

Fisher RA (1958) Cancer and smoking. Nature 182: 596

Gocyk W, Niklinski T, Olechnowicz H, Duda A, Bielanski W, Konturek PC, Konturek SJ (2000) Helicobacter pylori, gastrin and cyclooxygenase-2 in lung cancer. Med Sci Monit 6: 1085-1092

Goldgar DE, Easton DF, Cannon-Albright LA, Skolnick MH (1994) Systematic population-based assessment of cancer risk in first-degree relatives of cancer probands. J Natl Cancer Inst 86: 1600-1607

Goodman KJ, Correa P (2000) Transmission of Helicobacter pylori among siblings. Lancet 355: $358-362$

Guilford P, Hopkins J, Harraway J, McLeod M, McLeod N, Harawira P, Taite H, Scoular R, Miller A, Reeve AE (1998) E-cadherin germline mutations in familial gastric cancer. Nature 392: $402-405$

Hamilton SR, Aaltonen LA (2000) Pathology and Genetics of Tumours of the Digestive System. IARC Press: Lyon

Hemminki K, Jiang Y (2002a) Cancer risks among long-standing spouses. Br J Cancer 86: $1737-1740$

Hemminki K, Jiang Y (2002b) Familial and second gastric carcinomas: a nationwide epidemiologic study from Sweden. Cancer 94: 1157-1165

Hemminki K, Li X, Plna K, Granstrom C, Vaittinen P (2001a) The nationwide Swedish family-cancer database-updated structure and familial rates. Acta Oncol 40: $772-777$

Hemminki K, Vaittinen P, Dong C, Easton D (2001b) Sibling risks in cancer: clues to recessive or X-linked genes? Br J Cancer 84: 388-391

Hirohata T, Kono S (1997) Diet/nutrition and stomach cancer in Japan. Int J Cancer, Suppl 10: 34-36

Huang JQ, Sridhar S, Chen Y, Hunt RH (1998) Meta-analysis of the relationship between Helicobacter pylori seropositivity and gastric cancer. Gastroenterology 114: 1169-1179

Ji J, Hemminki K (2006) Second gastric cancers among patients with primary sporadic and familial cancers in Sweden. Gut 55: 896-898

Jochem VJ, Fuerst PA, Fromkes JJ (1992) Familial Barrett's esophagus associated with adenocarcinoma. Gastroenterology 102: 1400-1402

Jonsson S, Thorsteinsdottir U, Gudbjartsson DF, Jonsson HH, Kristjansson K, Arnason S, Gudnason V, Isaksson HJ, Hallgrimsson J, Gulcher JR, Amundadottir LT, Kong A, Stefansson K (2004) Familial risk of lung carcinoma in the Icelandic population. JAMA 292: 2977-2983

Kelley JR, Duggan JM (2003) Gastric cancer epidemiology and risk factors. $J$ Clin Epidemiol 56: 1 -9

Kerber RA, O'Brien E (2005) A cohort study of cancer risk in relation to family histories of cancer in the Utah population database. Cancer 103: 1906-1915

Kobayashi M, Tsubono Y, Sasazuki S, Sasaki S, Tsugane S (2002) Vegetables, fruit and risk of gastric cancer in Japan: a 10-year followup of the JPHC Study Cohort I. Int J Cancer 102: 39-44 
La Vecchia C, Ferraroni M, D’Avanzo B, Franceschi S, Decarli A, Baron JA (1995) Number of siblings and subsequent gastric cancer risk. Eur J Cancer Prev 4: 69-72

La Vecchia C, Negri E, Franceschi S, Gentile A (1992) Family history and the risk of stomach and colorectal cancer. Cancer 70: $50-55$

Lagergren J, Bergstrom R, Lindgren A, Nyren O (1999a) Symptomatic gastroesophageal reflux as a risk factor for esophageal adenocarcinoma. $N$ Engl J Med 340: 825-831

Lagergren J, Bergstrom R, Nyren O (1999b) Association between body mass and adenocarcinoma of the esophagus and gastric cardia. Ann Intern Med 130: $883-890$

Lagergren J, Ye W, Lindgren A, Nyren O (2000) Heredity and risk of cancer of the esophagus and gastric cardia. Cancer Epidemiol Biomarkers Prev 9: $757-760$

Lehtola J (1978) Family study of gastric carcinoma; With special reference to histological types. Scand J Gastroenterol Suppl 50: 3 - 54

Lichtenstein P, Holm NV, Verkasalo PK, Iliadou A, Kaprio J, Koskenvuo M, Pukkala E, Skytthe A, Hemminki K (2000) Environmental and heritable factors in the causation of cancer-analyses of cohorts of twins from Sweden, Denmark, and Finland. $N$ Engl J Med 343: 78-85

Lissowska J, Groves FD, Sobin LH, Fraumeni Jr JF, Nasierowska-Guttmejer A, Radziszewski J, Regula J, Hsing AW, Zatonski W, Blot WJ, Chow WH (1999) Family history and risk of stomach cancer in Warsaw, Poland. Eur J Cancer Prev 8: 223 - 227

Lorenzo Bermejo J, Hemminki K (2005) Familial lung cancer and aggregation of smoking habits: a simulation of the effect of shared environmental factors on the familial risk of cancer. Cancer Epidemiol Biomarkers Prev 14: $1738-1740$

Lynch HT, de la Chapelle A (2003) Hereditary colorectal cancer. $N$ Engl J Med 348: $919-932$

Madden PA, Pedersen NL, Kaprio J, Koskenvuo MJ, Martin NG (2004) The epidemiology and genetics of smoking initiation and persistence: crosscultural comparisons of twin study results. Twin Res 7: 82-97

Munoz SE, Ferraroni M, La Vecchia C, Decarli A (1997) Gastric cancer risk factors in subjects with family history. Cancer Epidemiol Biomarkers Prev 6: $137-140$

Ngoan LT, Yoshimura T (2003) Work, salt intake and the development of stomach cancer. Med Hypotheses 60: 552-556

Palli D, Galli M, Caporaso NE, Cipriani F, Decarli A, Saieva C, Fraumeni Jr JF, Buiatti E (1994) Family history and risk of stomach cancer in Italy. Cancer Epidemiol Biomarkers Prev 3: 15-18
Parkin DM, Bray F, Ferlay J, Pisani P (2001) Estimating the world cancer burden: Globocan 2000. Int J Cancer 94: 153-156

Parsonnet J, Hansen S, Rodriguez L, Gelb AB, Warnke RA, Jellum E, Orentreich N, Vogelman JH, Friedman GD (1994) Helicobacter pylori infection and gastric lymphoma. N Engl J Med 330: $1267-1271$

Pisani P, Parkin DM, Ferlay J (1993) Estimates of the worldwide mortality from eighteen major cancers in 1985. Implications for prevention and projections of future burden. Int J Cancer 55: 891 - 903

Siman JH, Forsgren A, Berglund G, Floren CH (1997) Association between Helicobacter pylori and gastric carcinoma in the city of Malmo, Sweden. A prospective study. Scand J Gastroenterol 32: 1215-1221

Storskrubb T, Aro P, Ronkainen J, Vieth M, Stolte M, Wreiber K, Engstrand L, Nyhlin H, Bolling-Sternevald E, Talley NJ, Agreus L (2005) A negative Helicobacter pylori serology test is more reliable for exclusion of premalignant gastric conditions than a negative test for current $\mathrm{H}$. pylori infection: a report on histology and $\mathrm{H}$. pylori detection in the general adult population. Scand J Gastroenterol 40: $302-311$

Tokuhata GK, Lilienfeld AM (1963) Familial aggregation of lung cancer in humans. J Natl Cancer Inst 30: 289-312

Uemura N, Okamoto S, Yamamoto S, Matsumura N, Yamaguchi S, Yamakido M, Taniyama K, Sasaki N, Schlemper RJ (2001) Helicobacter pylori infection and the development of gastric cancer. N Engl J Med 345: $784-789$

Wotherspoon AC, Ortiz-Hidalgo C, Falzon MR, Isaacson PG (1991) Helicobacter pylori-associated gastritis and primary B-cell gastric lymphoma. Lancet 338: $1175-1176$

Ye W, Ekstrom AM, Hansson LE, Bergstrom R, Nyren O (1999) Tobacco, alcohol and the risk of gastric cancer by sub-site and histologic type. Int J Cancer 83: 223 - 229

Ye W, Held M, Lagergren J, Engstrand L, Blot WJ, McLaughlin JK, Nyren O (2004) Helicobacter pylori infection and gastric atrophy: risk of adenocarcinoma and squamous-cell carcinoma of the esophagus and adenocarcinoma of the gastric cardia. J Natl Cancer Inst 96: $388-396$

Zhang Y, Liu X, Fan Y, Ding J, Xu A, Zhou X, Hu X, Zhu M, Zhang X, Li S, Wu J, Cao H, Li J, Wang Y (2006) Germline mutations and polymorphic variants in MMR, E-cadherin and MYH genes associated with familial gastric cancer in Jiangsu of China. Int J Cancer 119: $2592-2596$

zur Hausen H (1999) Viruses in human cancers. Eur J Cancer 35: 1174-1181 